\title{
Comparison of Resected Malignant Tumors of the Right- and Left-Sided Colon-Is There a Difference?
}

\author{
Erdinc Kamer ${ }^{1}[$
}

Received: 27 December 2021 / Accepted: 29 December 2021 / Published online: 3 February 2022

(c) Association of Surgeons of India 2022

\section{Dear Editor,}

I have been reading the article title "Comparison of Resected Malignant Tumors of the Right- and Left-Sided Colon-Is There a Difference?" in the Indian Journal of Surgery [1].

The authors compared right-sided colon cancer (RCC) and left-sided colon cancer (LCC) in their study and reported that they found significantly more mucinous adenocarcinoma histology types in right colon cancer, but, unlike the literature, there was no significant difference between the location of the tumor in the colon and overall survival [1]. The authors reported in their study that they considered rectosigmoid, ascending colon, and splenic flexure tumors as LCC, transverse colon, hepatic flexure, descending colon, and cecum tumors as RCC [1]. However, they did not report how they made this classification. As is known, this distinction between the right side and the left side colon is based on its embryological origins. The cecum, appendix, ascending colon, hepatic flexure, and proximal two-thirds of the transverse colon, called the right colon, originate from the midgut, while the distal third of the transverse colon, splenic flexure, sigmoid colon, and descending colon, called the left colon, originate from the hindgut [2,3]. Despite being in the same organ (colon), the right and left colon show themselves in two different ways in terms of histopathological, molecular, embryological, carcinogenesis, microbial population, and blood supply [3, 4]. I think that the most important reason why the authors did not find a difference in survival between right and left colon tumors in their studies, unlike the literature, is due to the inaccuracy of right colon and left colon classification. I look forward to the comments of the authors for this classification.

Best regards.

\section{Declarations}

Conflict of Interest The author declares no competing interests.

\section{References}

1. Biró A, Ternyik L, Somodi K et al (2021) Comparison of resected malignant tumors of the right- and left-sided colonis there a difference? Indian J Surg. https://doi.org/10.1007/ s12262-021-03209-y

2. Kalantzis I, Nonni A, Pavlakis K, Delicha EM, Miltiadou K, Kosmas C, Ziras N, Gkoumas K, Gakiopoulou H (2020) Clinicopathological differences and correlations between right and left colon cancer. World J Clin Cases 8(8):1424-1443. https://doi.org/10. 12998/wjcc.v8.i8.1424

3. Baran B, Ozupek NM, Tetik NY et al (2018) Difference between left-sided and right-sided colorectal cancer: a focused review of literature. Gastroenterol Res 11(4):264-273

4. Kılıç Ö, Gültekin Y, Biri İ, Yılmaz AU (2021) The prognostic factors on survival rates for patients with stage II-III colon cancer. Turk J Colorectal Dis 31:122-128

Publisher's Note Springer Nature remains neutral with regard to jurisdictional claims in published maps and institutional affiliations.
Erdinc Kamer

erdinc.kamer@gmail.com

1 University of Health Sciences, Izmir Faculty of Medicine, Clinic of General Surgery, İzmir, Turkey 